\title{
A APRENDIZAGEM DO JOVEM ADULTO A PARTIR DA SUA PERSPECTIVA E INTER-RELAÇÃO COM OS ARTEFATOS DIGITAIS: INDICADORES PARA PENSAR OS PROCESSOS FORMATIVOS NA UNIVERSIDADE
}

\author{
THE ADULT YOUTH'S LEARNING FROM THEIR PERSPECTIVE AND ITS INTER- \\ RELATIONSHIP WITH DIGITAL ARTIFACTS: \\ INDICATORS TO THINK TRAINING PROCESSES AT UNIVERSITY
}
EL APRENDIZAJE DEL JÓVEN ADULTO DESDE SU PERSPECTIVA E INTER-RELACIÓN CON LOS ARTEFACTOS DIGITALES:
INDICADORES PARA PENSAR LOS PROCESOS FORMATIVOS EN LA UNIVERSIDAD

\author{
Dirce Aparecida Foletto de Moraes ${ }^{1}$ \\ Claudia Maria de Lima²
}

RESUMO: Este artigo investiga a aprendizagem do estudante jovem adulto a partir da sua perspectiva e interrelação com os artefatos digitais e constitui-se como um estudo exploratório-explicativo, cujo público alvo foi uma turma de jovens ingressantes em uma universidade. As informações foram coletadas por meio de um questionário e analisadas sob a ótica da teoria da cognição distribuída e da teoria histórico-cultural. Os resultados elucidam que a aprendizagem conceitual, a partir da perspectiva dos estudantes, é construída socialmente por meio da participação e da colaboração, sempre mediadas por práticas e experiências coletivas e interativas, nas quais os artefatos digitais são auxiliares essenciais. Para tanto, necessitam de propostas formativas que vislumbrem uma prática diferenciada, apoiada na construção coletiva e na mediação, na qual o uso dos artefatos tem espaço garantido.

PALAVRAS-ChAVE: Aprendizagem. Jovem adulto. Processos formativos. Artefatos digitais.

ABSTRACT: This article investigates the learning of young adult students their perspective and interrelationship with digital artifacts and it is an exploratory-explanatory study, whose target audience was a group of young people entering a public university. The information was collected through a questionnaire and analyzed based on the theory of distributed cognition and historical-cultural theory. The results elucidate that conceptual learning, from the student perspective, is socially constructed through participation and collaboration, always mediated by collective and interactive practices and experiences, in which digital artifacts are essential aids. For this purpose, they need training proposals that envisage a differentiated practice, based on collective construction and mediation, in which the use of artifacts has guaranteed space.

KEYWORDS: Learning. Young adult. Training processes. Digital artifacts.

RESUMEN: Este artículo investiga el aprendizaje del estudiante joven adulto desde su perspectiva y interrelación con los artefactos digitales y se constituye como un estudio exploratorio-explicativo, cuyo público objetivo fue una clase de jóvenes ingresantes en una universidad. Las informaciones fueron recolectadas por medio de un cuestionario y analizadas bajo la óptica de la teoría de la cognición distribuida y de la teoría histórico-cultural. Los resultados aclaran que el aprendizaje conceptual, desde la perspectiva de los estudiantes, es construido socialmente a través de la participación y de la colaboración, siempre mediadas por prácticas y experiencias

\footnotetext{
${ }^{1}$ Submetido em: 30/05/2018 - Aceito em: 1706/2018 - Publicado em: 18/01/2019
}

v.9


colectivas e interactivas, en las cuales los artefactos digitales son auxiliares esenciales. Para ello, necesitan propuestas formativas que atisban una práctica diferenciada, apoyada en la construcción colectiva y en la mediación, en la cual el uso de los artefactos tiene espacio garantizado.

PALABRAS Clave: Aprendizaje. Joven adulto. Procesos formativos. Artefactos digitales.

\section{INTRODUÇÃO}

O jovem adulto do século XXI está experimentando uma nova etapa no processo históricocultural a partir das apropriações e das relações estabelecidas com os artefatos digitais. As diferentes práticas e experiências vivenciadas pelos jovens com os dispositivos tecnológicos presentes em seu contexto permitem que estes passem a exercer sobre aqueles uma função extraordinária como ferramenta cultural mediadora, capaz de reformular as práticas socioculturais e os modos de produção, aumentando as possibilidades de ampliação das capacidades cognitivas.

No entanto, ao focalizarmos o contexto educacional, o que se percebe é que mesmo com um cenário tão explicitamente diferenciado, no qual os artefatos se tornaram protagonistas e os jovens seus maiores usuários, as práticas vivenciadas na universidade têm se mostrado praticamente inalteradas, como se fosse um mundo à parte. Apesar de muitos pesquisadores ressaltarem tal necessidade, nossa experiência em um curso de formação de professores nos permite afirmar que essa não tem sido uma preocupação colocada em relevo na universidade.

Diante disso, ao pensarmos nos processos formativos desses sujeitos na universidade, não podemos anular as formas de relação social e cultural e as produções de sentidos que os jovens vêm desenvolvendo na contemporaneidade a partir da inter-relação com os artefatos digitais e como isso tem refletido na sua forma de pensar, de aprender e de se desenvolver.

Outro aspecto importante é levar em consideração o que e como pensa o principal ator do processo acadêmico: o próprio aluno. Vários estudos e pesquisas focam a formação do professor, as necessidades pedagógicas e o como ensinar; já a aprendizagem é interpretada, muitas vezes, como uma atividade autônoma, na qual o sujeito é o principal responsável por planejar, executar e avaliar seu próprio desempenho e, diferentemente da educação voltada para a infância, o professor tem pouca preocupação e responsabilidade sobre o que e como esses sujeitos pensam, bem como com as diferenças em suas formas de aprender (SMITH; POURCHOT, 1998).

Assim, entendemos que essa realidade apresenta uma lacuna que precisa de respostas para que a instituição cumpra seu papel enquanto espaço de formação que se encontra dentro de em um contexto em constantes mudanças socioculturais. Nessa perspectiva, desenvolvemos

n.3 1 p.632-649


este estudo, o qual tem como objetivo investigar a aprendizagem do estudante jovem adulto em fase inicial de formação profissional a partir da sua perspectiva e inter-relação com os artefatos digitais. A modalidade de pesquisa, exploratório-explicativa, norteou o estudo que foi realizado com uma turma de ingressantes na universidade. Para coletar os dados, optamos por um questionário on-line e, para o tratamento destes, apoiamo-nos na análise de conteúdos.

Importa destacar que, com este estudo, pretendemos oferecer indicadores que possam colaborar para a compreensão da aprendizagem do estudante do século XXI e que, assim, se repense os processos formativos oferecidos a esse público nas universidades.

\section{A APRENDIZAGEM DO JOVEM ADULTO}

Em nosso contexto sociocultural, entendemos como jovem adulto aquele que deixou a adolescência e aproxima-se dos 20 anos. Juridicamente, ele passa a responder por seus atos, deixa de ser tutelado por um responsável, torna-se mais independente e autônomo. Essa fase da vida envolve novas responsabilidades, mudanças e escolhas nas relações sociais, pessoais, profissionais e acadêmicas, que se constituem em caminhos incertos, transições e enfrentamentos não vividos até então.

Apesar de algumas especificidades, não podemos universalizar ou categorizar o sujeito jovem adulto, pois, além da diversidade de mudanças pessoais que vivencia, em cada sociedade e época histórica, ele vai constituindo-se enquanto jovem adulto a partir das experiências, do que lhe for exigido e permitido em seu meio.

No tocante aos aspectos sociológicos, pode ser considerado como adulto o sujeito que se responsabiliza por seus atos, escolhe uma profissão, casa-se ou inicia uma relação afetiva mais intensa. É nessa fase da vida que o sujeito vai deparar-se com muitas e diferentes situações conflitantes, que até então não faziam parte das suas experiências de vida, e enfrentá-las. Papalia, Olds e Feldman (2006) consideram que o jovem adulto inicia o processo de muitas descobertas pessoais, sociais e culturais, experimenta novas formas de vida e de conhecimentos.

Especificamente sobre a aprendizagem do jovem adulto, esta se diferencia daquela da criança pelas necessidades, experiências e conhecimentos acumulados, pelas visões de mundo, por uma maior capacidade de reflexão que o jovem agrega em sua bagagem cultural e também pelos ambientes em que esta ocorre. Essas especificidades implicam "[...] diferentes habilidades e dificuldades (em comparação com a criança) e, provavelmente, maior 
capacidade de reflexão sobre o conhecimento e sobre seus próprios processos de aprendizagem" (OLIVEIRA, 2009, p. 200).

De acordo com Palácios (1995, p. 310), os adultos possuem e conseguem manter um bom nível de desenvolvimento cognitivo ao longo de sua vida. Sobre os jovens adultos (em média, aos 20 anos), o autor aponta que "[...] são mais capazes de dividir sua atenção entre diversos estímulos, o que provavelmente implica uma boa dose de flexibilidade". Já em relação à memória, o autor entende que, para esse público, o processo é semelhante ao da atenção, destacando que eles têm "[...] boas capacidades mnésicas, tanto no que se refere à memória a curto prazo, como nas relacionadas com a memória a longo prazo" (PALÁCIOS, 1995, p. $310)$.

No entanto, vários autores (LEMME, 1995; PALÁCIOS, 1995; SMITH; POURCHOT, 1998; OLIVEIRA, 2009; SANTOS, 2012) destacam que, nas pesquisas realizadas durante o século $\mathrm{XX}$, a aprendizagem e o desenvolvimento cognitivo do adulto não foram o foco central de educadores e psicólogos, tornando-se, assim, um campo que ainda carece de investigações e de compreensão em alguns aspectos.

A realidade não se alterou muito, pois as pesquisas que se voltam para a etapa do desenvolvimento ainda são escassas na contemporaneidade, principalmente aquelas referentes ao desenvolvimento cognitivo do jovem adulto. Para uma compreensão mais intensa sobre a temática, realizamos um levantamento em quatro bases de dados: Portal de Periódicos da Coordenação de Aperfeiçoamento de Pessoal de Nível Superior (CAPES), Banco de teses e dissertações da CAPES, Banco Digital Brasileiro de Teses e Dissertações (BDTD) e SciELO, considerando o período de 2006 a 2016. As palavras-chave selecionadas para a pesquisa foram: aprendizagem, estudante adulto, educação superior. Assim, encontramos 82 trabalhos, sendo 7 teses, 31 dissertações e 44 artigos.

Pela busca pudemos identificar um número expressivo de estudos com o foco na educação de jovens e adultos, algumas pesquisas voltadas para o adolescente e pouco para o estudante universitário, especificamente em fase inicial de formação. Os estudos enfocam os seguintes temas: a aprendizagem do adolescente, jogos educativos, leitura, desempenho, aprendizagem centrada no estudante, currículo e formação em docência.

Pesquisas que envolvem especificamente o jovem estudante universitário são apresentadas em sete dissertações, sendo quatro voltadas aos estudantes de cursos de educação a distância, três teses e um artigo, os quais destacam como foco de investigação os seguintes temas: estratégias pedagógicas, dificuldades de aprendizagem e avaliação da aprendizagem. Diante desses dados entendemos a necessidade premente de continuar e ampliar as pesquisas que tenham como foco esse sujeito e sua aprendizagem. 
No campo teórico, percebemos que algumas correntes se propõem a explicar os processos cognitivos e a aprendizagem do adulto. Dentre os poucos estudos voltados para essa fase do desenvolvimento, destacamos a perspectiva piagetiana como referência, a qual entende que a formação da mente alcança seu ápice ao atingir o estágio das operações formais, geralmente na adolescência, e tem como característica a formação do pensamento abstrato. Esse seria praticamente o ponto final do desenvolvimento cognitivo, com poucas modificações, pois a maturidade do pensamento já foi alcançada e não há mais como avançar. Para essa teoria, o desenvolvimento do indivíduo é entendido como um processo e o contexto no qual ele está inserido não têm relevância.

Lemme (1995) considera que essa é uma visão quantitativa do desenvolvimento, e que uma visão qualitativa estaria relacionada à continuidade do desenvolvimento da cognição, no sentido de alcançar formas complexas do pensamento. Isso porque o desenvolvimento do sujeito vai se modificando a partir das condições e experiências que ele vivencia no decorrer da vida e em seu contexto histórico e cultural. Com isso, “[...] os adultos não só adquirem mais conhecimento, eles também desenvolvem novas formas, qualitativamente diferentes de pensar" (LEMME, 1995, p. 150).

Nesse estágio, denominado pós-formal, o pensamento se torna mais maduro, amplo e flexível, além de continuar desenvolvendo-se ao longo da vida. Segundo Papalia, Olds e Feldman (2006, p. 532), esse se caracteriza "[...] pela capacidade de lidar com a incerteza, com a inconsistência, com a contradição, com a imperfeição e com a conciliação”. Isso contraria a ideia de estabilidade e o declínio no pensamento ao atingir o estágio das operações formais. O pensamento pós-formal vai tornando-se mais complexo e rico em experiências vivenciadas ao passo que o adulto assume novas e diferentes responsabilidades e certos papéis sociais. Assim, por não seguir uma lógica formal, o pensamento toma a forma dialética e passa a dirigir as ações do sujeito adulto.

Dentre os pesquisadores que postulam a continuidade do desenvolvimento cognitivo, destacamos Basseches (2005), que, ancorado nos estudos de Riegel, caracteriza o pensamento pós-formal como dialético. O autor se apoia, também, em Marx para explicar o pensamento dialético, e apresenta-o como o esforço para analisar e compreender o mundo, no qual o desenvolvimento é resultado da interação e da mediação. Ao contrário do pensamento formal, que conta com um sistema fechado e individual, no qual o pensamento é estruturado sistematicamente, o pensamento dialético consiste em constantes ambiguidades compostas pela interação e mediação, "[...] importante para o desenvolvimento sócio-cognitivo do adulto" (BASSECHES, 2005, p. 56).

Alguns pesquisadores buscam explicar o desenvolvimento cognitivo e a aprendizagem do sujeito adulto a partir de uma perspectiva contextual, tomando como base a teoria histórico-

\begin{tabular}{l|l} 
n. 3 & p.632-649
\end{tabular}

set./dez. 2018 eISSN 2178-8359 
cultural (BONK; KIM, 1998; OLIVEIRA, 2004; 2009; SANTOS, 2012). Nessa abordagem, a discussão sobre os processos cognitivos distancia-se do indivíduo isolado para focar as mediações nas atividades no meio sociocultural em diversas situações e espaços. Sob essa perspectiva, o desenvolvimento cognitivo é entendido, então, como o resultado das mediações entre o sujeito e o contex to no decorrer da vida.

Vigotski (2005, p. 115), principal autor da teoria histórico-cultural, não teve como foco central de suas investigações o sujeito adulto, mas, contrariando pesquisas experimentais que afirmavam a incapacidade de aprender conceitos novos, reconheceu o potencial desses sujeitos ao mencionar que "[...] os adultos, como bem se sabe, dispõem de uma grande capacidade de aprendizagem".

Placco e Souza (2006) defendem que o estudante adulto aprende de muitas formas, e considera que sua aprendizagem se caracteriza pela experiência, por aquilo que lhe é significativo e proposital. Para as autoras, a aprendizagem é um processo que "[...] resulta da interação entre adultos, quando experiências são interpretadas, habilidades e conhecimentos são adquiridos e ações são desencadeadas" (PLACCO; SOUZA, 2006, p. 17).

O jovem adulto passa por um período de transição entre a adolescência e a vida adulta, pois começa a deixar alguns papéis e a assumir outros. Esse sujeito está iniciando a vida acadêmica na universidade, a vida profissional e, às vezes, conjugal. No contexto em que está inserido, realiza atividades e vivencia diversas situações e, dependendo da qualidade do elemento mediador a que tem acesso, pode avançar em seu desenvolvimento. Assim, o diferencial em relação à criança está na bagagem que vai sendo constituída para chegar à idade adulta com um processo mental complexo, composto por experiências e conhecimentos, sejam eles tácitos ou científicos.

As experiências que o jovem adulto vivencia envolvem as atividades e o meio sociocultural e passam a exercer papel fundamental na aprendizagem e no desenvolvimento cognitivo. Em virtude disso, faz-se necessário considerar os ambientes e os espaços com os quais ele interage (BONK; KIM, 1998), bem como analisar como cada um atua no seu desenvolvimento.

$\mathrm{Na}$ atualidade, percebe-se que as diferentes interfaces e as ferramentas de compartilhamento disponíveis nos artefatos digitais favorecem variadas experiências aos jovens adultos, como o trabalho coletivo e a aprendizagem mais interativa, colaborativa e autônoma, bem como promovem a troca de experiências e a ajuda mútua na busca por um objetivo comum (BOTTENTUIT JUNIOR; COUTINHO, 2009; COLL; MAURI; ONRUBIA, 2010). Assim, entende-se que esse jovem não atua, não vive e não aprende sozinho, pois realiza suas tarefas cognitivas ancorado nas redes sociais e nas relações estabelecidas no ciberespaço, onde cria

n.3

p.632-649

set./dez. 2018

eISSN 2178-8359 
comunidades, ensina e aprende por meio das interações e experiências que vivencia (MONEREO; POZO, 2010).

Esse sujeito se tornou, também, autor e produtor de conteúdos com os artefatos digitais, não apenas consumindo informação, mas produzindo e emitindo seus conteúdos, seja por meio da produção de vídeos, de comunidades, dos $b \log s$, das redes sociais ou de grupos formados em seus dispositivos móveis. Com isso, toda a gama de experiências que o jovem adulto vivencia direciona para mudanças nas capacidades mentais. Lalueza e Camps (2010, p. 60) afirmam que "[...] as transformações cognitivas decorrentes dos artefatos digitais não advêm da aquisição da ferramenta em si, mas do conjunto de práticas em que seu uso se introduz [...]" e do papel mediador que essa ferramenta passa a exercer.

Para que possamos propor práticas formativas ao jovem contemporâneo, que inicia seus estudos na universidade, faz-se necessário entender como esse sujeito pensa, aprende e relaciona-se com o objeto de conhecimento e com seu contexto, pois a ideia de uma aprendizagem linear e isolada não se sustenta mais em uma sociedade mediada pelos artefatos digitais, visto que a colaboração e a interação são conceitos presentes nas práticas culturais realizadas entre os jovens contemporâneos.

\section{MÉTODO}

Como parte exploratória da pesquisa de doutoramento de uma das autoras, a qual buscou investigar os processos formativos dos jovens adultos, focalizamos um grupo cultural específico, heterogêneo e não universalizado, constituído, em sua maioria, por jovens que estão deixando a adolescência e ingressando na vida adulta.

Aqui, apresentaremos os dados coletados por meio de um questionário composto de questões dissertativas e objetivas sobre como o estudante, participante da pesquisa, entende sua aprendizagem. O público alvo foi um grupo de 41 estudantes que, após assinarem o Termo de Consentimento Livre e Esclarecido (TCLE), responderam ao questionário. Essas informações foram importantes pois ajudaram-nos a perceber de que forma esses sujeitos achavam que aprendiam mais e melhor, bem como suas experiências vividas e os elementos que os auxiliavam na elaboração conceitual.

Assim, para melhor organizar os dados que nos ajudariam a caracterizar a aprendizagem do aluno jovem a partir da sua perspectiva, orientamo-nos pelos seguintes indicadores: especificidades que podem explicar a aprendizagem de conceitos científicos do estudante adulto; formas de realizar as atividades para garantir a aprendizagem de conceitos; e ambientes e meios favoráveis para aprender conceitos em espaços acadêmicos e em espaços

n.3

p.632-649

set./dez. 2018

eISSN 2178-8359 
distintos deste. Os dados foram categorizados com o apoio da técnica de análise de conteúdos proposta por Bardin (1977) e analisados sob a luz da teoria da cognição distribuída e histórico-cultural.

\section{RESULTADOS E DISCUSSÕES}

O primeiro indicador nos encaminhou a solicitar aos participantes que descrevessem uma experiência significativa de aprendizagem em sua trajetória escolar, para que, a partir dessa, pudéssemos identificar elementos relacionados à forma de aprender conceitos. Os dados aqui apresentados referem-se à frequência do número de argumentos, e não de participantes. Estes encaminharam a constatação de quatro categorias: didática do professor $(58,39 \%)$, interação com as tecnologias (31,9\%), aula expositiva (5,55\%) e esforço do estudante $(4,46 \%)$. Ressaltamos que alguns estudantes não tinham experiências significativas e, por isso, relataram como gostariam que fossem suas práticas de aprendizagem de conceitos.

A categoria mais representativa foi didática do professor, com 58,39\% de frequência. Essa categoria se relaciona à oportunidade de vivenciar diversas experiências com o objeto de conhecimento, relacionando teoria e prática, ou seja, o "aprender fazendo" e entender o conceito na realidade, com destaque para abordagens diferenciadas de ensino, aulas dinâmicas, atividades coletivas, debates, troca de conhecimentos e interação com os colegas. Os estudantes valorizam o professor enquanto sujeito que, a partir de sua didática, consegue transmitir os saberes culturalmente elaborados de forma que estes sejam apropriados, e não apenas reproduzidos.

Esses jovens, que vivem inúmeras experiências fora do contexto escolar, atuam, interagem, ensinam e aprendem em suas comunidades, mas também anseiam por uma didática que ultrapasse a perspectiva estática da exposição do ensino e esperam que o espaço educativo também lhes proporcione algumas experiências de interação, conforme o seguinte excerto: "Formas diferentes de se ensinar ajudam bastante [...] ajudam o aluno a se interessar e aprender, no meu caso adoro coisas diferentes que fazem pensar e raciocinar e fazer eu ver as coisas com uma visão diferente" (A30).

Para os estudantes pesquisados, a aprendizagem é social, e não individual, e ocorre a partir de práticas coletivas e interativas, em um processo "intermental" que se tornará "intramental" (WERTSCH; TULVISTE, 2013).

Vigotski (2003) explica que é a partir da interação e da cooperação que o aprendizado vai despertar processos internos de desenvolvimento, por isso são elementos fundamentais no processo educativo. A teoria da cognição distribuída toma como base as ideias desse autor

n.3

p.632-649

set./dez. 2018

eISSN 2178-8359


para defender a interação entre os sujeitos e a interação destes com os artefatos, pois, ao interagirem, os sujeitos partilham e distribuem conhecimentos individuais que se tornam coletivos.

Diante da complexidade que é a formação de conceitos, ao tentar optar pelo caminho do ensino direto e simplificado, não se chega a resultados muito relevantes, “[...] exceto o verbalismo vazio, uma repetição de palavras [...] que simula um conhecimento dos conceitos correspondentes, mas que na realidade oculta um vácuo" (VIGOTSKI, 2005, p. 104). Assim, segundo esse autor, o ensino tem como função criar zonas de desenvolvimento iminente e provocar processos internos no desenvolvimento do sujeito, os quais devem ocorrer sempre em situações de interação e cooperação, e por que não de criação de redes de aprendizagem.

A segunda categoria identificada foi a interação com as tecnologias, com 31,9\% de frequência. Os estudantes destacam a interação com os artefatos como elemento fundamental para aprender. Para esses jovens, os diferentes recursos, como vídeos, músicas, filmes, slides, pesquisas e trabalhos realizados com e na internet podem colaborar mais com a aprendizagem de conceitos do que aulas somente expositivas. Estes deixam claro que a aprendizagem ocorre em parceria, não só com outros sujeitos, mas, também, com ferramentas com as quais eles interagem em seu meio. Salomon (1993) explica que a atividade realizada em parceria com os artefatos inteligentes favorece a distribuição de cognições e deixa resíduos cognitivos que ajudam os sujeitos a se autorregular.

Em outro estudo, Salomon, Perkins e Globerson (1991) expressam que mudanças cognitivas podem ser favorecidas a partir do envolvimento do estudante e da parceria estabelecida com algum artefato em situações de aprendizagem. No entanto, os autores destacam que não é o uso de qualquer ferramenta ou em qualquer situação que isso vai ocorrer, mas somente com aquelas que permitem a realização de novas tarefas e diferentes operações cognitivas.

Karasavvidis (2002) exemplifica a diferença entre o uso de lápis e papel e o de um programa de computador para realizar uma tarefa que envolva gráficos e tabelas. No primeiro caso, o estudante precisa de um tempo maior para projetar tais gráficos, já no segundo, sua preocupação se volta para explorar os recursos gráficos que o computador oferece para desenvolver sua tarefa. O seguinte excerto ilustra: "As aulas deveriam ser mais em slides, filmes, debates, vídeos e não só o professor falando na frente, pois isso se torna muito cansativo" (A24).

Para Cole e Engestrom (1993) e Vigotski (2003), desde a infância o sujeito faz uso de recursos auxiliares para atingir suas metas e realizar suas atividades, no entanto, ao adentrar o espaço escolar, isso nem sempre é considerado. 
O jovem ao qual nos referimos convive com os artefatos digitais e opera mentalmente a partir da interação que estabelece com o meio, com o ambiente e com os artefatos. Salomon (1997) expressa que nossa mente está interligada com os artefatos e suas formas simbólicas moldam a maneira como construímos significados, como usamos nossas capacidades mentais e percebemos o mundo. Como exemplo, o autor ressalta que algumas tecnologias auxiliam na aprendizagem, mas não necessariamente alcançam as formas simbólicas das informações. Já ao lançarmos mão de diferentes formas simbólicas de representar o mundo, como a imagem e o vídeo, temos a oportunidade de aprender algo diferente.

A aula expositiva foi outra categoria identificada, totalizando 5,55\%. Bem menos expressiva que as anteriores, esta se refere à exposição clara, à orientação e ao encadeamento das ideias organizadas pelo professor como contributo para a aprendizagem de conceitos. A aula expositiva é um momento importante do contexto educacional, pois, ao fazer uma exposição sobre o conceito estudado, o professor apresenta suas ideias ou fundamentos teóricos de forma sistematizada e supostamente diferente do que o aluno pensaria. Assim, pode contribuir para que o estudante confronte suas ideias ou eleve seu nível de compreensão sobre o objeto de estudo se este for organizado a partir de uma intencionalidade e não consistir em uma exposição linear e unidirecional.

No entanto, precisa intencionar a complexificação do pensamento do sujeito que aprende e, para tanto, implica a maneira pela qual o processo de transmissão dos conteúdos se dará em sala de aula (MARTINS, 2013), ou seja, depende das condições, das situações de aprendizagem proporcionadas e, mais exclusivamente, do tipo de atividade, de aula e do encaminhamento metodológico proposto. A autora reforça a ideia explicitando que o "desenvolvimento do pensamento é uma conquista advinda de condições que o promovam e o requeiram - e, como tal, depende em alto grau das dimensões qualitativas da formação escolar" (MARTINS, 2013, p. 35).

A última categoria se refere, estritamente, ao esforço do estudante. Também não muito expressiva, com 4,16\% de frequência, esta considera que a aprendizagem depende exclusivamente do empenho e da dedicação do aluno. Esses alunos se sentem totalmente responsáveis por sua aprendizagem e desconsideram as interferências externas que podem ocorrer nesse processo. No entanto, falta-lhes a compreensão de que aprender conceitos científicos não é um processo simples e direto, que ocorre a partir da dedicação da pessoa, mas é uma atividade mental complexa, mediada por outros conceitos que, segundo Vigotski (2005), formam-se a partir das condições internas e externas em que todas as funções mentais são envolvidas.

Enquanto futuros professores, é importante que possam vivenciar na universidade experiências que os ajudem a problematizar tais questões e a desconstruir algumas

p.632-649

set./dez. 2018 eISSN 2178-8359


concepções para que não saiam dela com uma formação tão fragilizada. Para Martins (2013, p. 289, grifo do original),

[...] quanto maior a fragilidade dessa formação maior o embotamento da síntese a favor da precariedade, que deixa de se referir apenas à 'parcela da realidade que disporá como alunos' passando a expressar como precariedade na compreensão acerca da própria realidade.

A aprendizagem de conceitos não é um processo simples de repetição de palavras, mas "[...] é o resultado de uma atividade complexa, em que todas as funções básicas tomam parte [...]" (VIGOTSKI, 2005, p. 50), por isso requer um bom ensino, com uma didática que valoriza a aprendizagem enquanto prática social coletiva, na qual a interação e as trocas bidirecionais, o compartilhamento e o confronto de ideias tenham espaço garantido. Assim, fica claro que o ensino de conceitos não pode ser um simples processo de instrução, mas requer intencionalidades didáticas que promovam operações mentais capazes de favorecer $o$ desenvolvimento do pensamento. Para tanto, entendemos que, para aprender conceitos, faz-se necessário ponderar os "[...] meios pelos quais essa operação é realizada [...]. Devemos considerar o uso de instrumentos, a mobilização dos meios apropriados sem os quais o trabalho não poderia ser realizado" (VIGOTSKI, 2005, p. 69).

Diante das categoriais apresentadas nessa questão, podemos considerar que os jovens participantes da pesquisa entendem a aprendizagem de conceitos a partir da interação entre os sujeitos, da interação destes com os artefatos e com o professor e em diferentes situações, assim como preconizam a teoria da cognição distribuída. Esses estudantes indicam que necessitam do professor e das aulas expositivas para aprender, mas precisam atuar de forma mais ativa e autônoma nas situações de aprendizagem.

Vale ressaltar que os dados aqui apresentados não se caracterizam como a realidade vivida no cotidiano acadêmico, mas advêm de uma coletânea em que os sujeitos indicam como gostariam que fosse a prática educativa para aprender conceitos.

Outra pergunta buscou entender a melhor forma de realizar as atividades para garantir a aprendizagem de conceitos, bem como as razões que atribuem a essas opções. Nessa questão, as respostas se referem ao número de sujeitos, e não à frequência de respostas. Para 83\% (30 estudantes), as atividades deveriam ser realizadas integrando momentos individuais e em grupo, para 13,9\% (5 alunos), sempre em grupo e, somente para 2,8\% (1 estudante), as atividades deveriam ser realizadas sempre em parceria com um colega. Ninguém optou por realizar as atividades sempre individualmente.

A maioria dos estudantes (83\%) considera que aprende conceitos em sala em situações que integram atividades individuais e em grupo. Para esses jovens, os momentos individuais favorecem a reflexão, a elaboração de um pensamento, a análise da sua aprendizagem e a 
formação de uma ideia própria, mas eles entendem que o trabalho não pode se limitar a situações individuais, pois, ao trabalharem em grupo, podem interagir, trocar ideias e conhecimentos, socializar, compartilhar, debater e até mesmo divergir. Com isso, aprendem com outro, refazem o pensamento elaborado individualmente, formam novas ideias e conceitos, conforme o excerto: "As atividades em sala de aula são bem mais compreendidas quando há um debate em grupo, porém tendo momentos também de reflexão individual" (A24).

Os estudantes expressam que sentem a necessidade de elaborar um pensamento a partir do seu próprio entendimento, mas este não fica limitado, pois a interação com o outro vai favorecer uma nova síntese e uma nova compreensão sobre o conceito.

Para aqueles que consideram que para aprender deveriam sempre trabalhar em grupos $(13,9 \%)$, as razões estão relacionadas ao entendimento de que, dessa forma, eles se sentem mais a vontade e podem ajudar-se mutuamente. Assim, além de sempre contar com alguém, aprendem com o outro e têm a oportunidade de discutir, confrontar e compartilhar suas dúvidas e ideias: "Não consigo me "encontrar" quando estou estudando sozinha, pois ficaria muito mais difícil de tirar as minhas dúvidas. Às vezes um outro aluno consegue nos fazer entender aquilo que o professor está explicando" (A16).

A categoria aprender sempre em parceria com um colega foi expressa por um estudante (totalizando 2,8\%) e está relacionada à ideia de ter sempre alguém ao seu lado, dando apoio e ajudando em todos os momentos.

As categorias evidenciam, de alguma forma, a necessidade de interação com outras pessoas para que possam aprender conceitos. Nessa interação, ocorre a partilha, a troca e a distribuição da cognição. Tais dados vão ao encontro do proposto por Pea (1993) ao defender que o conhecimento é construído socialmente por meio da participação, da colaboração e de diálogos entre os sujeitos, em busca de um propósito comum, ou ainda no confronto e nas diferenças de pensamentos que cada um apresenta. $\mathrm{O}$ autor ainda explica que, dessa forma, ocorre a distribuição social da cognição.

As práticas anunciadas pelos jovens indicam que eles consideram a parceria um elemento importante para o aprendizado. Com isso, fica claro que os processos formativos não se constituem no isolamento, na individualidade, mas resultam de uma ação cooperativa e orientada por outros (KARASAVVIDIS, 2002), em um ambiente exclusivamente social.

Nessa pesquisa, interessava, também, identificar os ambientes ou outros meios considerados favoráveis para aprender conceitos para além da sala de aula. A questão central, aqui, foi entender os tipos de atividades, as experiências, as situações e as formas como aprendem,

n.3


bem como os artefatos com os quais esses jovens interagem no contexto em que estão inseridos. Isso porque, segundo a teoria da cognição distribuída, o ambiente é considerado um recurso cognitivo em que o processo mental é dividido, compartilhado e mediado pelas interações entre os sujeitos e com as ferramentas que dela fazem parte.

Assim, os espaços identificados que possibilitam a aprendizagem para os jovens são: a internet, com $32,15 \%$ de frequência, o convívio social com $25 \%$, as atividades práticas com $23,21 \%$, o trabalho com $8,92 \%$, os livros com $7,15 \%$ e os meios de comunicação com $3,57 \%$ de frequência. Esses dados se referem ao número de argumentos, e não ao número de sujeitos.

A internet é a categoria considerada pelos estudantes como um espaço de aprendizagem fora do ambiente escolar, com 32,15\% de frequência nas respostas. Para esses jovens, é possível aprender pela internet por meio da diversidade de opções que nela encontram, como tirar dúvidas, aprender algo novo, buscar ou trocar informações com outras pessoas.

Esta categoria evidencia que, além de servir como ambiente de interação social e entretenimento, a internet é percebida por uma parcela do grupo como espaço para aprendizagem de conceitos. Estes expressam que podem assistir videoaulas, pesquisar e ler sobre o assunto ou tema, trocar informações em redes sociais ou mesmo publicar algo. Isso demonstra a ação dos estudantes frente ao objeto de conhecimento, pois eles fazem uso das possibilidades que esse artefato oferece para aprender.

A internet, como canal de distribuição de informação e mediadora das interações entre os jovens, vem ganhando credibilidade como espaço de muitas possibilidades de aprendizagem a partir do grande repertório de conteúdos disponível e das ferramentas de interação e produção que oferece aos sujeitos. As múltiplas interfaces e as práticas de uso desse artefato conduzem os jovens ao entendimento dessa ferramenta não só como recurso, mas como parceira de aprendizagem. Nesse ambiente, o jovem adulto aprende investigando, interagindo, confrontando pensamentos e ouvindo o que os outros dizem. A postura do jovem aqui apresentada sinaliza uma atitude ativa e autônoma por parte desse sujeito que aproveita o potencial dos instrumentos para mediar sua aprendizagem.

O convívio social, com $25 \%$ dos argumentos, sugere que a interação com outras pessoas em diferentes lugares e situações e a oportunidade de trocar saberes com colegas e com pessoas com mais experiência em encontros, bate-papos e viagens sejam consideradas ambientes de aprendizagem. Tais dados evidenciam que os jovens aprendem trocando informações e conhecimentos, interagindo com o outro, confrontando ideias e dialogando. A teoria da cognição distribuída preconiza que os processos mentais se desenvolvem na ação e na interação, assim, quando os sujeitos estão interagindo, eles trocam cognições, ampliam e

\begin{tabular}{l|l} 
n.3 & p.632-649
\end{tabular}

set./dez. 2018

eISSN 2178-8359 
criam zonas de desenvolvimento iminente, que, segundo Bonk e Kim (1998), funcionam, inicialmente, como um sistema de apoio, mas aos poucos vão sendo internalizadas e tornamse processos de autorregulação no adulto.

A terceira categoria, com $23,21 \%$ de frequência, considera a "prática" como possibilidade de aprendizagem. Para os estudantes, a oportunidade de vivenciar situações e experiências, participar de projetos, acompanhar o trabalho de outras pessoas e visitar lugares são exemplos de como eles aprendem fora do espaço escolar.

A categoria prática significa a oportunidade de participar, vivenciar experiências, enfrentar novos desafios, experimentar e avançar em seus processos cognitivos. Com isso, o sujeito adquire novas aprendizagens e transforma seus processos cognitivos. Para Rogoff (1998, p. 196), por meio da participação em atividades práticas a pessoa se desenvolve cognitivamente, "[...] mudando sua forma de compreender, perceber, notar, pensar, lembrar-se, classificar, refletir, estabelecer e solucionar problemas, planejar e assim por diante [...]".

O trabalho também é considerado um ambiente de aprendizagem, com 8,92\% de frequência nas respostas dos jovens. Estes consideram que as novas tarefas e os desafios encaminham para a busca de mais conhecimentos. O ambiente de trabalho é um espaço que muitas vezes desafia o sujeito a realizar novas e diferentes atividades, a usar artefatos e, ainda, a interagir e divergir com as formas de pensar de outras pessoas.

Assim, se tiver oportunidade de lidar com essas ou outras situações, o sujeito adulto vai agregar em sua bagagem novas ideias e aprendizagens, além de novas formas de atividade cognitiva que vão resultar em desenvolvimento (LEMME, 1995). Diante disso, é possível considerar que no ambiente de trabalho o adulto aprende por meio de desafios, da resolução de situações-problema, das interações que estabelece e das experiências que vivencia.

Os livros são considerados como alternativa de aprendizagem fora do espaço escolar. Essa categoria se apresenta com 7,15\% de frequência nas respostas. Para os estudantes, os livros podem ajudar a aprender e a aprofundar o conhecimento porque são o suporte e o apoio para adquirir conhecimentos. Os meios de comunicação aparecem com uma alternativa menos representativa entre os jovens, com 3,57\% de frequência nas respostas.

Os jovens consideram os livros e os meios de comunicação como elementos auxiliares que os ajudam a aprender conceitos, ou seja, são artefatos que exercem papel mediador das atividades cognitivas dos sujeitos.

De modo geral, os jovens participantes da pesquisa indicam que aprendem investigando, interagindo, colaborando, vivenciando experiências, enfrentando desafios e situações-

n.3 1 p.632-649

set./dez. 2018

eISSN 2178-8359 
problema mediados por diferentes situações e recursos. Diante disso, podemos considerar que o jovem adulto também aprende conceitos fora do contexto escolar e de formas diferenciadas daquelas que vive em sala de aula. Com isso, não só aprendem, mas também se desenvolvem cognitivamente.

Bonk e Kim (1998) expressam que as mudanças socioculturais decorrentes da inserção e do uso dos artefatos digitais promovem diferentes padrões de produção e novas formas de aprendizagem, como a colaboração, a interação, as trocas, a resolução de problemas e os desafios entre outros, bem como reforçam que são aspectos que precisam ser considerados na universidade.

Assim, precisamos entender o jovem adulto como alguém que traz em sua bagagem várias experiências e diferentes formas de aprender, dos seus contextos de aprendizagem para a universidade.

Os dados apontam, a partir dessas categorias, que as experiências interpessoais vividas pelos jovens são importantes no seu processo formativo. Para isso, eles se apoiam em diversos elementos do contexto, e não somente nas práticas em sala de aula, demonstrando, assim, que os espaços de aprendizagem se ampliaram e expandiram-se (BONK; KIM, 1998). Além disso, os jovens expressam que os instrumentos e símbolos de um contexto medeiam os pensamentos e o funcionamento mental (PEA, 1993).

\section{CONSIDERAÇÕES FINAIS}

De forma geral, os dados levantados neste estudo indicam, claramente, uma ambiguidade entre o que os estudantes apontam em relação às formas como aprendem e o que eles vivem, de fato, nos espaços acadêmicos, pois essa não é a realidade que temos nas instituições educativas. Apesar de apontarem a importância da colaboração, de modo geral, não trabalham em parceria, trocando ideias e ajudando-se mutuamente, salvos alguns momentos de trabalho em grupo.

Podemos supor que esse seja, realmente, um indicativo de como gostariam que fosse a dinâmica das aulas e um alerta sobre a forma como aprendem, mas não o que eles vivem de fato, e, desse modo, entendemos que esses sujeitos anseiam por uma prática diferenciada, apoiada na construção coletiva, na qual o uso dos artefatos tem espaço garantido, superando a ideia de que a construção de conhecimento se dá na individualidade.

Assim, concluímos que os dados apresentados e analisados neste questionário expressam que a aprendizagem conceitual, a partir da perspectiva dos estudantes, é construída socialmente

\begin{tabular}{l|l} 
n.3 & p.632-649 \\
\hline
\end{tabular}

set./dez. 2018

eISSN 2178-8359 
por meio da participação e da colaboração, sempre mediada por práticas e experiências coletivas e interativas, nas quais os artefatos digitais são auxiliares essenciais.

Neste sentido, ao pensarmos nos processos de formação conceitual dos jovens adultos da contemporaneidade, precisamos levar em consideração que esses sujeitos necessitam de intervenções didáticas diferenciadas, apoiadas na construção coletiva e na mediação, nas quais o uso dos artefatos tem espaço garantido como auxiliares de suas aprendizagens.

\section{REFERÊNCIAS}

BARDIN, Laurence. Análise de conteúdo. Lisboa: Edições 70, 1977.

BASSECHES, Michael. The development of dialectical thinking as an approach to integration. Integral Review, v. 1, p. 47-63, 2005. Disponível em: http://integralreview.org/documents/Development\%20of\%20Dialectical\%20Thinking\%201,\%202005.pdf. Acesso em: 12 ago. 2017.

BONK, Curtis Jay; KIM, Kyung A. Extending sociocultural theory to adult learning. In: SMITH, M. Cecil; POURCHOT, Thomas. Adult learning and development: perspective from educational psychology. London: Lawrence Erlbaum Associates, Inc, 1998. P. 67-88.

BOTTENTUIT JUNIOR, João Batista; COUTINHO, Clara. Comunicação Educacional: do modelo unidireccional para a comunicação multidireccional na sociedade do conhecimento. In: CONGRESSO DA SOCIEDADE PORTUGUESA DE CIÊNCIAS DA

COMUNICAÇÃO, 5., 2009, Braga. Atas... Braga: Universidade do Minho, 2009. Disponível em: repositorium.sdum.uminho.pt/bitstream/1822/7770/1/Sopcom.pdf. Acesso em: 23 dez. 2017.

COLE, Michael; ENGESTRÖM, Yrjö. A cultural-historical approach to distributed cognition. In: SALOMON, Gavriel. Distributed cognitions: psychological and educational considerations. Cambridge: CUP, 1993. P. 01-46.

COLL, Cesar; MAURI, Teresa; ONRUBIA, Javier. A incorporação das tecnologias de informação e da comunicação na educação: do projeto técnico-pedagógico às práticas de uso. In: COLL, Cesar; MONEREO, Carles (Orgs.). Psicologia da educação virtual: aprender e ensinar com as tecnologias da informação e da comunicação. Porto Alegre: Artmed, 2010. P. 66-93.

KARASAVVIDIS, Ilias. Distributed cognition and educational practice. Journal of Interactive Learning Research, Creta, v. 13, p. 11-29, 2002.

LALUEZA, Luis José; CAMPS, Isabel Crespo e Silva. As tecnologias da informação e da comunicação e os processos de desenvolvimento e socialização. In: COLL, Cesar;

\begin{tabular}{l|l} 
n.3 & p.632-649
\end{tabular}

set./dez. 2018

eISSN 2178-8359 
MONEREO, Carles (Org.). Psicologia da Educação Virtual: aprender e ensinar com as Tecnologias da Informação e da Comunicação. Porto Alegre: Artmed, 2010. P. 47-65.

LEMME, Barbara Hansen. Development in adulthood. Boston: Allyn \& Bacon, 1995.

MARTINS, Ligia Marcia. O desenvolvimento do psiquismo e a educação escolar: contribuições à luz da psicologia histórico-cultural e da pedagogia histórico-crítica. Campinas: Autores Associados, 2013.

MONEREO, Carles; POZO, Juan Ignacio. O aluno em ambientes virtuais. In: COLL, Cesar; MONEREO, Carles (Org.). Psicologia da educação virtual: aprender e ensinar com as tecnologias da informação e da comunicação. Porto Alegre: Artmed, 2010. P. 97-135.

OLIVEIRA, Marta Kohl de. Ciclos de vida: algumas questões sobre a psicologia do adulto. Educação e Pesquisa, São Paulo, v. 30, n. 2, p. 211-229, maio/ago. 2004. Disponível em: https://www.revistas.usp.br/ep/article/view/27931/29703. Acesso em: 24 fev. 2016.

OLIVEIRA, Marta Kohl de. Cultura e psicologia: questões sobre o desenvolvimento do adulto. São Paulo: Editora Hucitec, 2009.

PALÁCIOS, Jesús. O desenvolvimento após a adolescência. In: COLL, César; PALÁCIOS, Jesús; MARCHESI, Álvaro (Org.). Desenvolvimento psicológico e educação. v. 1. Porto Alegre: Artes Médicas, 1995. P. 306-321.

PAPALIA, Diane E.; OLDS, Sally Wendkos; FELDMAN, Duskin. Desenvolvimento humano. Porto Alegre: Artmed, 2006.

PEA, Roy. Practices of distributed intelligence and designs for education. In: SALOMON, Graviel. Distributed cognitions: psychological and educational considerations. Cambridge: CUP, 1993. P. 47-87.

PLACCO, Vera Maria Nigro de Souza; SOUZA, Vera Lúcia Trevizan de. (Org.) Aprendizagem do adulto professor. São Paulo: Loyola, 2006.

ROGOFF, Barbara. Observando a atividade sociocultural em três planos: apropriação participatória, participação guiada e aprendizado. In: WERTSCH, James V. Estudos socioculturais da mente. Porto Alegre: Artmed, 1998. P. 122-136.

SALOMON, Gavriel. Distributed cognitions: psychological and educational considerations. Cambridge: CUP, 1993. P. 47-87.

SALOMON, Gavriel. Of mind and media: how culture's symbolic forms affect learning and thinking. Phi Delta Kappan, v. 78, n. 5, p. 375-380, 1997.

SALOMON, Gavriel; PERKINS, David; GLOBERSON, Tamar. Partners in cognition: extending human intelligence with intelligent technologies. Educational Researcher, v. 20, p. 2-9, 1991.

\begin{tabular}{l|l} 
n.3 & p.632-649
\end{tabular}


SANTOS, Ezicléia Tavares dos. Do aprender ao ensinar: significados construídos pelo futuro docente no aprendizado com e sobre as tecnologias digitais. 2012. $336 \mathrm{f}$. Tese (Doutorado em Educação) - Universidade Federal de Juiz de Fora, Juiz de Fora, 2012.

SMITH, M. Cecil; POURCHOT, Thomas. Adult learning and development: perspective from educational psychology. London: Lawrence Erlbaum Associates, Inc, 1998.

VIGOTSKI, Lev Semenovich. A formação social da mente. São Paulo: Martins Fontes, 2003.

VIGOTSKI, Lev Semenovich. Pensamento e linguagem. São Paulo: Martins Fontes, 2005.

WERTSCH, James V., TULVISTE, Peeter. L. S. Vygotsky e a psicologia evolutiva contemporânea. In: DANIELS, Harry (Org.). Uma introdução a Vygotsky. São Paulo: Edições Loyola, 2013. P. 61-82.

\section{Agradecimentos}

Ao Programa de Apoio a Capacitação Docente das Instituições Públicas de Ensino Superior do Paraná Doutorado (Acordo Capes/Fundação Araucária). Chamada Pública nº 13/2014.

\section{Sobre as Autoras}

1 Dirce Aparecida Foletto de Moraes - Doutora em Educação pela Universidade Estadual Paulista - Júlio de Mesquita Filho. Professora da Universidade Estadual de Londrina. Brasil. E-mail: dircemoraes@ uel.br - ORCID: http://orcid.org/0000-0002-1392-1605

${ }^{2}$ Claudia Maria de Lima - Professora da Universidade Estadual Paulista - Júlio de Mesquita Filho. Brasil. E-mail: claudiamarialima@uol.com.br - ORCID: http://orcid.org/0000-0003$\underline{4979-5070}$ 